\title{
Towards an Ontological Learner's Modeling During and After the COVID-19 Pandemic
}

\author{
Amina OUATIQ ${ }^{1}$, Kamal El Guemmat ${ }^{2}$, Khalifa Mansouri ${ }^{3}$, Mohammed Qbadou ${ }^{4}$ \\ SSDIA Laboratory, ENSET Mohammedia \\ Hassan II University of Casablanca \\ Mohammedia, Morocco
}

\begin{abstract}
The health crisis and the unprecedented upheaval in the education systems which it caused are far from being over, consequently, the adaptation of the learning experience is most needed, and it should take into consideration the criteria of this specific crisis and its impact on the physical and mental health of the learners. In this article, we aimed to present an ontologybased learner model that will bring together the pedagogical and psychological characteristics, but also the health risks generated by the epidemic on the learners, following a KnowledgeEngineering Methodology. We developed an ontology that combines the IMS-LIP standard features and the learner characteristic. It is ready for different uses in different systems and situations during and after the COVID-19 pandemic, and it will give a global representation of the learner in order to allow him to get the best-adapted courses.
\end{abstract}

Keywords-Learner model; personalization; adaptive learning; ontology; COVID-19

\section{INTRODUCTION}

With the pandemic and the closure of schools and universities, in order to control the spread of the virus. Different distance learning approaches have been developed to ensure the continuity of education. The transition from face-toface to distance education with little to no experience has generated an educational crisis in addition to the health and economic crisis, especially in countries with a low Human Development Index [1].

Even before the pandemic, teachers always tried to prepare and offer adapted courses to their learners, taking into consideration that learners are the center of the learning experience, and that every learner is special and learns distinctively according to his learning style, cognitive style, previous knowledge, as well as his behavior and motivation [2]. Whether in hybrid, or distance education adaptive systems are the best tools to provide learners with the best learning objects based not only on their preferences but also on their needs noting that learners themselves might not even be aware of their own needs, particularly in times of crisis such as this pandemic.

Adaptive systems utilize individual informations available on learners, in order to offer a specific and accurate learning experience to each learner. Therefore, the learner model should be the most radical part because it helps to understand the learner and give him an active role in his learning [3].
There are several ontological learner models that discuss various characteristics such as the learner's learning style, performance [4-7], motivation [8], knowledge [6, 9]. However, during the pandemic, and being in lockdown, other characteristics related to COVID-19 and to learner's mental health has emerged. Yet there is no model that addresses those characteristics or the impact of the crisis time on the mental state of learners.

The absence of learner models that take into account the learners' mental health and the impact of times of crisis on their well-being is the problem that this article tries to solve by developing an ontological learner model that represent relevant pedagogical, psychological, and physical characteristics, using the health crisis related to the COVID-19 pandemic and the resulting isolation impacts.

This article will present a learner model ontology, which will not only feature the characteristics of each learner such as knowledge, background, goals, interests, learning styles, and learning activities [10], but also other properties relevant to the time of the pandemic, and helpful to cope with the effects of confinement on the mental health of learners, as if the learner or a member of his family is affected by COVID-19, the presence of the symptoms of anxiety and/or depression, as well as if he lives in a cluster site. The proposed ontology will allow the reuse of data, it is evaluated and structurally validated [11], so all the requirements and constraints are met to make use of it.

The rest of this article is organized as follows. The following section will present the standard learner models and their attributes, and the effects of COVID-19 on the learner's mental health. It will then describe the methodology of designing the ontology in the third section. And in the fourth section, the learner model ontology will be presented. Later in the fifth section some examples of uses of the ontology will be suggested. And will conclude in the last section.

\section{RELATED WORK}

\section{A. Learner Model}

The learner model is a representation of cognitive and noncognitive characteristics of the learner. This model allows the representation and management of each learner with his own individual properties and characteristics $[12,13]$. 
The learner model is different from the learner profile which only contains static data. While the model contains both static and dynamic data [12]. So, the profile can be the basis of the model, which is a more like an abstract representation, and the ontologies allow to define a common vocabulary on an abstract domain, and to specify the complex relations between the concepts of domain [14]. This is among the reasons they have become one of the most widely used learner modeling approaches [15], and due to its advantages, such as ease of reuse, availability of effective design tools, etc. [16].

The purpose of learner modelling is to give a complete and accurate description of all aspects of the user's behavior [17]. User models in adaptive hypermedia are generally compatible with learner standards. There are several standard learner models like IMS ACCLIP (Accessibility for Learning Information Package), IMS RDCEO (Reusable Definition of Competency or Educational Objective), and others but the most used are PAPI learner (Public and Private Information) and IMS-LIP $[18,19]$ and they're the models that the next section presents, they organize a certain number of user data according to different structures.

1) PAPI Learner standard (Public and Private Information) aims to specify the semantics and syntax of learner's information (knowledge acquisitions, preferences, performance, skills, and relationships with other learners, etc.) [20]. In the PAPI model, a learner profile is defined by:

- PAPI Learner Performance: organize the information related to the learner's performance,

- PAPI Learner Personal: present personal information about the learner,

- PAPI Learner Preference: provide details Information related to learner preferences,

- PAPI Learner Portfolio: a collection of the learner's work "portfolio",

- PAPI Learner Relations: report relational information, relationships with other users (professors, other learners, etc.),

- PAPI Learner Security: register Security information like Passwords, keys, etc.

2) IMS LIP standard (Learner Information Package) is based on a data model that describes the characteristics required of a learner for general use. It defines a user data structure that can be imported or exported between interoperable systems [21]:

- Accessibility: Describes general accessibility (language skills, disabilities, eligibility requirements, and learning preferences),

- Activity: describes all relevant activities related to learning,

- Affiliation: gives information about the professional organizations to which the learner belongs,

- Competency: the learning skills acquired,
- Goal: assemble information about the learning goal, and other learner objectives such as personal goals and inspiration,

- Identification: learner's personal data (name, address, contact, ...),

- Interest: information describing the learner's hobbies and recreational activities,

- QCL (Qualifications, Certifications \& Licenses): lists the qualifications, certifications, and licenses obtained by the learner,

- Relationships: learner's relationship with other resources (identification, accessibility, activities, interests, etc.),

- Security key: security data (passwords, access rights, and security keys assigned to the learner),

- Transcript: presents a summary of the academic results.

IMS-LIP and PAPI Learner present a basic representation of the learner model. Yet IMS-LIP is a more stable extension of PAPI, with other specifications that are more detailed and more likely to contain other features [5, 22]. Without forgetting that the attributes of the two models are optional and reusable. Subsequently, to design a learner model for a particular situation or system, it is enough to have a certain number of predefined attributes, some of which may be optional, and to provide a framework to facilitate the creation of nonpredefined attributes [23].

\section{B. Covid-19 and Mental Health}

The Quarantine, isolation, and social distancing have an impact on people's psychological well-being. Several studies have detected the harmful damage that the pandemic has on mental health: anxiety, fear, frustration, loneliness, anger, boredom, depression, stress, etc. [24].

Sanguino et al. found out that $18.7 \%$ of the people they diagnosed revealed depressive symptoms, $21.6 \%$ anxiety, and 15.8\% Post-Traumatic Stress Disorder (PTSD) [25]. Under the same theme the results of Cao et al. were related specifically to students because they are among the groups of people that were most affected by the pandemic damages. They state that $24.9 \%$ of learners suffered from anxiety due to the COVID-19 epidemic and almost $1 \%$ of them suffered from severe anxiety [26].

Anxiety, depression, and PTSD are the most mental disorders found among students in times of crisis. Thus, the approach proposed will focus on adding these disorders to the learner model. The question that now arises is how to diagnose learners to find out if they are at risk of having a mental disorder. For this, screening tests and rating scales are useful in order to identify the presence of a disorder and to quantify its severity if it occurs [27].

1) Rating scales for depression: There are several scales and psychological tests that examine the presence and the severity of depression; the three golden standards are The Hamilton Rating Scale for Depression (HAM-D), The Beck 
Depression Inventory (BDI), and Inventory of Depressive Symptomatology (IDS) [28].

The Hamilton depression scale (HAM-D) is among the most used scales to test depression clinically [29] with an optimized 17 item, it tests the existence and sorts the severity of depression: no depression (0-7); mild depression (8-16); moderate depression (17-23); to severe depression ( $\geq 24$ ) [30]. The second one is The Beck Depression Inventory (BDI) which is a self-report scale designed to measure the severity of depressive symptoms; the first version contained 21 items associated to relative scores [31]. The third is the Quick Inventory of Depressive Symptomatology (QIDS), is a selfreport version of the IDS 28 items that should be administered clinically, QIDS is a short questionnaire that takes 5 to 7 minutes with 16 items that reveal the severity of symptoms, and symptomatic change. The severity of depression ranges from 0 to 27 as follows (0-5) None, (6-10) Mild, (11-15) Moderate, (16-20) Severe, (21-27) Very severe [32].

2) Rating Scales for anxiety: Specialists can administrate criterions of general or specific anxiety disorder to get an idea of the level of anxiety of a patient [33]. There are several measures of anxiety, and in this section, we will focus on measures of general anxiety (GAD) such as The Hamilton Rating Scale for Anxiety (HAM-A) which is a 14-item anxiety symptom scale, administered by a clinician to measure the occurrence and severity of the disorder from 0 (not present) to 4 (very severe) [34]. And the Generalized Anxiety Disorder (GAD-7) scale, a 7-questions scale in its first version as the name suggests which was subsequently developed into a 13questions questionnaire adding questions to assist the duration of symptoms [35]. GAD-7 has demonstrated to have good reliability to test for anxiety disorders and to sort out symptoms of mild, moderate, and severe anxiety [35-37].

3) Rating Scales for post-traumatic stress disorder $(P T S D)$ : A trauma is "the experience, witnessing, or confronting of an event that involves actual or threatened death or serious injury, or other threat to one's physical integrity" [38] and for the person to react with "intense fear, helplessness, or horror" [38], it exists plenty of scales to assess the PTSD symptoms like Clinician-Administered PTSD Scale (CAPS), an established interview of 10 items that assess the symptoms. The total severity score for the CAPS (CAPS-total) ranges between 0 and 136. Although it's time-consuming [39]. And the PTSD Checklist (PCL) which is a self-report scale that consists of 17 items to rate symptoms from 1 to 5 according to their severity [40], it helps to distinguish between patients at high or low risk of having an anxiety disorder [41].

\section{Ontology Construction Methodology}

Ontologies represent complex concepts and they have the possibility of being reusable and extensible and even interoperable with content on the web. The use of ontologies to model learners subsequently facilitates the adaptation of educational objects by adaptive systems. The learner model ontology proposed is structured according to the IMS Learner standard (IMS LIP), which allows to take the attribute needed, since all elements in LIP are optional and even add other attributes that will be pertinent to our context [14-13].

Our aim is to connect potential mental disorders with the relevant characteristics of the learner, in addition to data related to Covid-19 infection.

\section{A. Process}

In this work, we followed the Knowledge-Engineering Methodology which is an iterative process in 7 steps. It starts with determining the domain and scope of the ontology and leads us to create our instances [14].

1) Determine the domain and scope of the ontology: The first step is to define the scope of the ontology by deciding on which questions it should provide answers to (competency questions) [42]:

\section{Q1: What are the essential characteristics of a learner?}

Q2: What are the effects of the pandemic on the learner's mental health?

Q3: Is the learner or a family member was affected by the virus?

From these questions, we can see that the ontology will include various information about the learner both essential information out of the crisis and information about the learner's mental health and detect if he was affected by the pandemic or in the general time of crisis.

2) Consider reusing existing ontologies: In this step, we have studied the standard learner models and chosen the most used which are presented in section 2 . We will reuse the attributes of the IMS-LIP standard because of its stability and its ability to exchange all types of information about the learner, so it can manage other functionalities required by new uses [22]. In addition to existing ontological modules such as Labib et al. who have worked on learning styles [4]. Zine et al. who regroup several standard models in order to realize its ontology [18]. Or [43] and [5] who have developed two ontologies in order to model lifelong learning with different relevant components. We have also taken into account the concept of reuse when developing our ontology, to ensure the possibility of reusing it in different systems, contexts and scenarios, for example, at different times of crisis such as natural disasters or even personal crises such as the death of a loved one, and not only in the case of a pandemic, which has inspired our research.

3) Enumerate important terms in the ontology: This step, as its name indicates, makes it possible to list the terms related to the ontology (terms that we would discuss about and their properties, the relationship between them, etc.). To create a useful list, we started by writing terms related to learner modelling, we scanned articles on learner modelling [3, 10, $12,44,45]$, and on mental disorders that are relevant to our research $[27,36,38,46]$ which we discussed in the second part. In addition to the various glossaries. Table I arranges some terms we have listed. 
TABLE I. COLLECTION OF RELEVANT TERMS

\begin{tabular}{|l|l|l|}
\hline Learner & Mental disorder & Pandemic \\
\hline Knowledge & Anxiety & Covid-19 \\
\hline Level & depression & Confinement \\
\hline competence & PTSD & isolation \\
\hline characteristic & FEAR & virus \\
\hline identity & symptoms & infected \\
\hline skill & scale & transmission \\
\hline performance & Standard assessment & Cluster site \\
\hline degree & Severity & health crisis \\
\hline
\end{tabular}

4) Define the classes and the class hierarchy: We started by grouping similar items into classes using a combination of top-down and bottom-up approaches. First, we chose the most relevant and independent terms, then organize the specific information. We have tried to keep some attributes of the IMS-LIP in order to meet the standard. At the end of this step, we have obtained the following classes:

- Information: this class regroup the different IMS-LIP attributes.

- Mental disorder: represents the mental disorders that learners may have due to the pandemic and confinement.

- COVID-19 History: to determine if the learner or a family member is or has already been infected with the virus, has spent a period of confinement, lives in cluster site (Place where the number of cases is higher than expected).

Fig. 1 shows the different classes of our ontology.

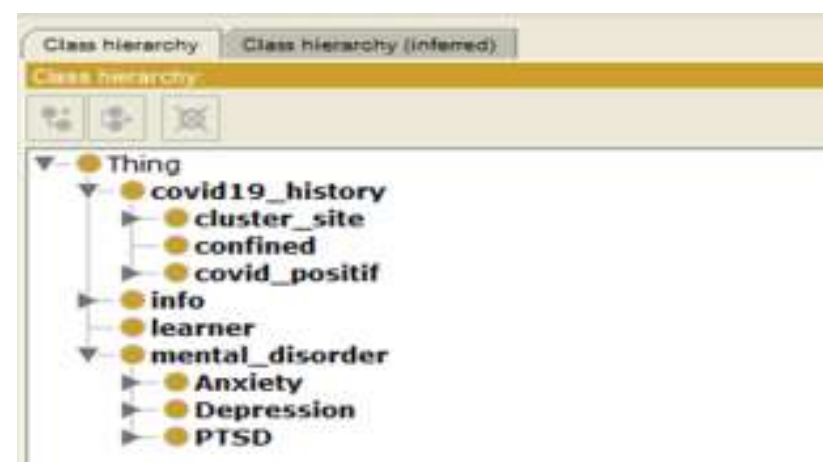

Fig. 1. The Upper-Level Concepts.

5) Define the properties of classes: After selecting classes, the next step is determining the properties/relationships to specify taxonomies for classes and properties. (e.g., "has_crisis"," has_covid_history,etc).
6) Define the facets of the slots: In this step we determine the slots cardinalities, type values, its range and domain, to limit the possible value for example "anxiety_level" is of type symbol and take the values (mild, moderate, severe).

7) Create instances: The last step is creating individual instances of classes in the hierarchy as well as the slot values for specific classes.

\section{ONTOLOGY IMPLEMENTATION}

We chose the Web Ontology Language (OWL) of the World Wide Web Consortium's Web to encode our ontology and Protégé 4.3 ontologies editor to develop it. OWL helped us to specify the taxonomy for the classes and the different properties. Then we checked it with Protégé standard reasoner.

The proposed approach evolves from the standard learner model and existing ontologies cited in the previous section. However, it integrates other useful information about the COVID-19 pandemic and learner mental health and ensures a better representation of the learner.

We have organized the characteristics of our learner model into facets. The class of learner as shown in Fig. 2, is the key concept of our ontology, it includes all the details about the learner, and it is associated with other classes via has_info, has_crisis, and has_covid.

Info (Cf. Fig 3): this class answers the first question asked when establishing the scope of the ontology on the essential characteristics of the learner. Therefore, the class is composed of the different attribute of IMS LIP Identification as defined in the second section, Activity, Transcript, Interest, Competency, Accessibility, Security, and Affiliation. For example, as shown in the figure bellow the subclass QCL has degree which contains all the degrees of the learner (High School, Bachelor, Master, Doctoral) and his certification. The subclass competency class the competence of the learner in one of three levels $\{$ beginner, intermediate, expert $\}$.

Mental_disorder (Cf. Fig. 4): The class presents relevant information about the learner's mental health after a crisis. Citing the troubles which might affect the learners. To test or diagnose the learner we choose some psychological scales as described in Section 2. This class answers the second question related to the effects of the pandemic and the confinement on the learner's mental health.

Covid_history (Cf. Fig. 5): The last important class is the one related to COVID-19 history (the last question of the first step). This class allow us to determine if a learner or a member of his family is affected by the virus, if he's confined in the moment and also if he lives in a cluster site (A specific site where the number of cases of an infectious disease that occurs over a specific period of time is higher than the expected number).

\footnotetext{
${ }^{1}$ https://www.btb.termiumplus.gc.ca/publications/covid19-eng.html
} 


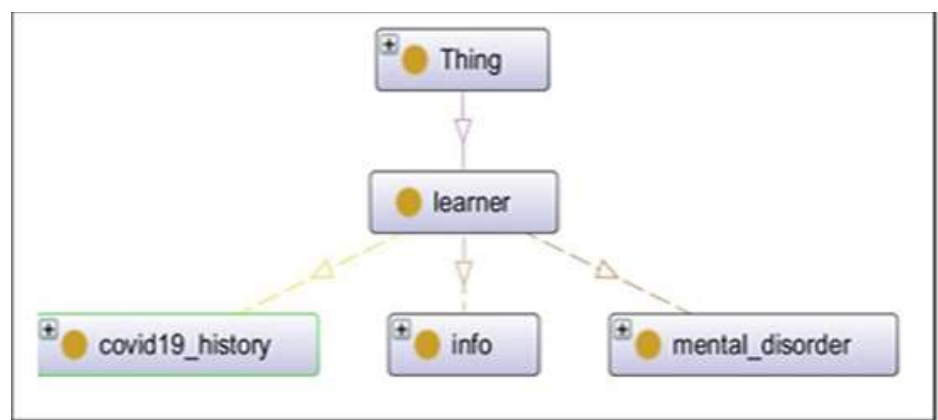

Fig. 2. The Learner Graphs.

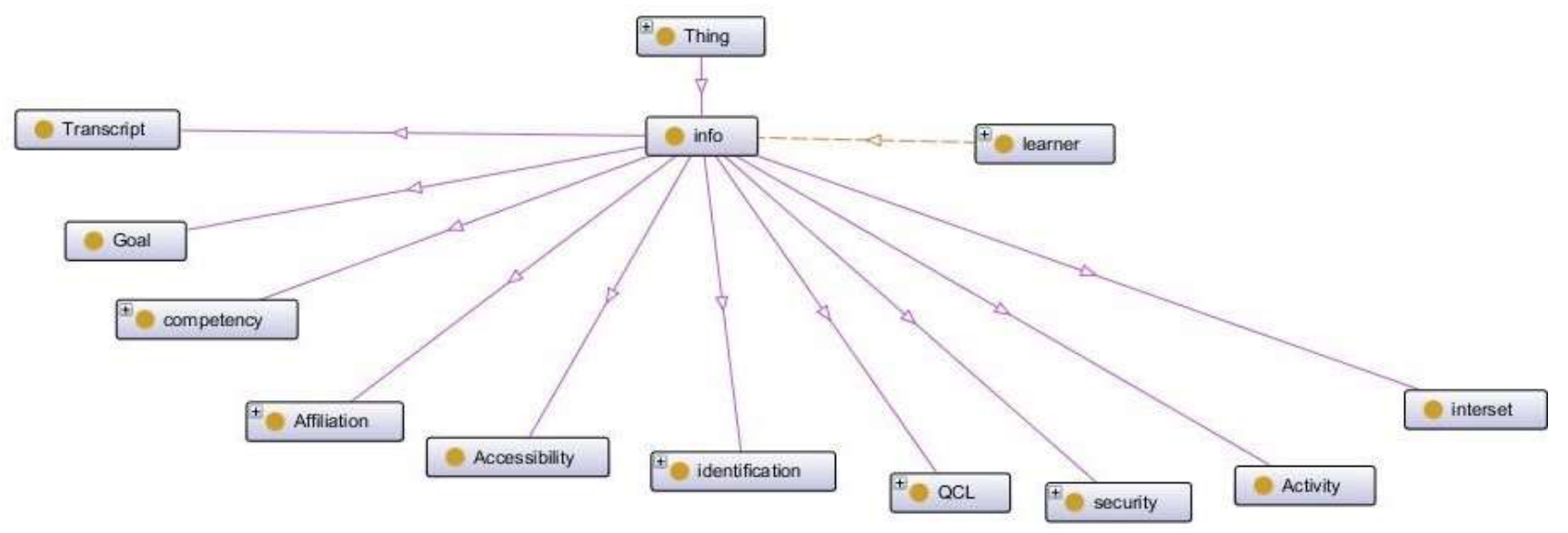

Fig. 3. The Info Class.

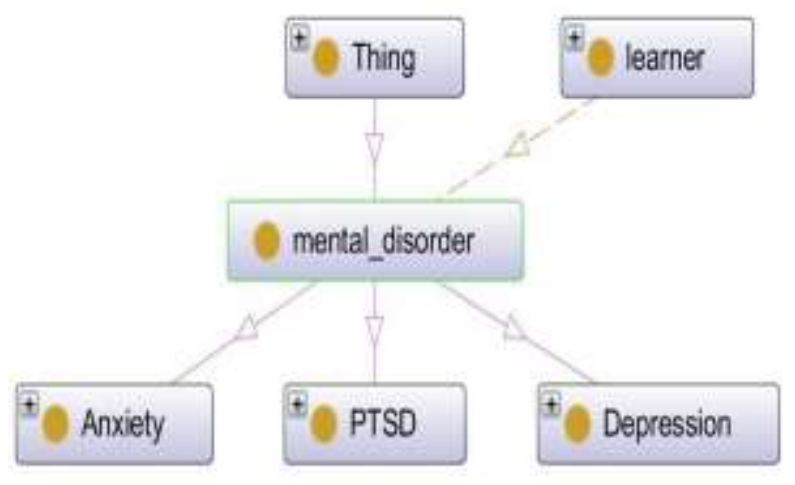

Fig. 4. Mental Disorder Class.

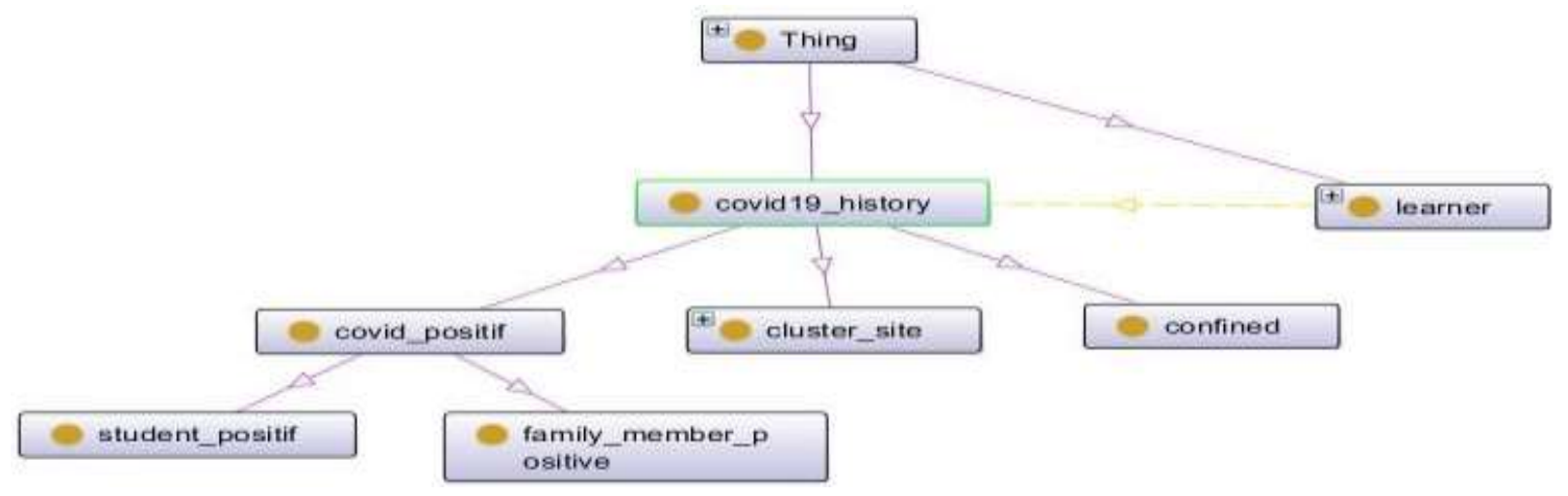

Fig. 5. Covid_History Class. 
Fig. 2 to 5 illustrate the graphical representation of the proposed learner ontology. They capture all the concepts that describe learner profiles and are intended to answer questions about learner characteristics in times of crisis and beyond. Our ontology is IMS-LIP compliant.

Our main objective is to relate potential mental disorders to relevant learner characteristics, including data related to Covid19 infection as shown in Fig. 6, which details the hierarchies of our ontology.

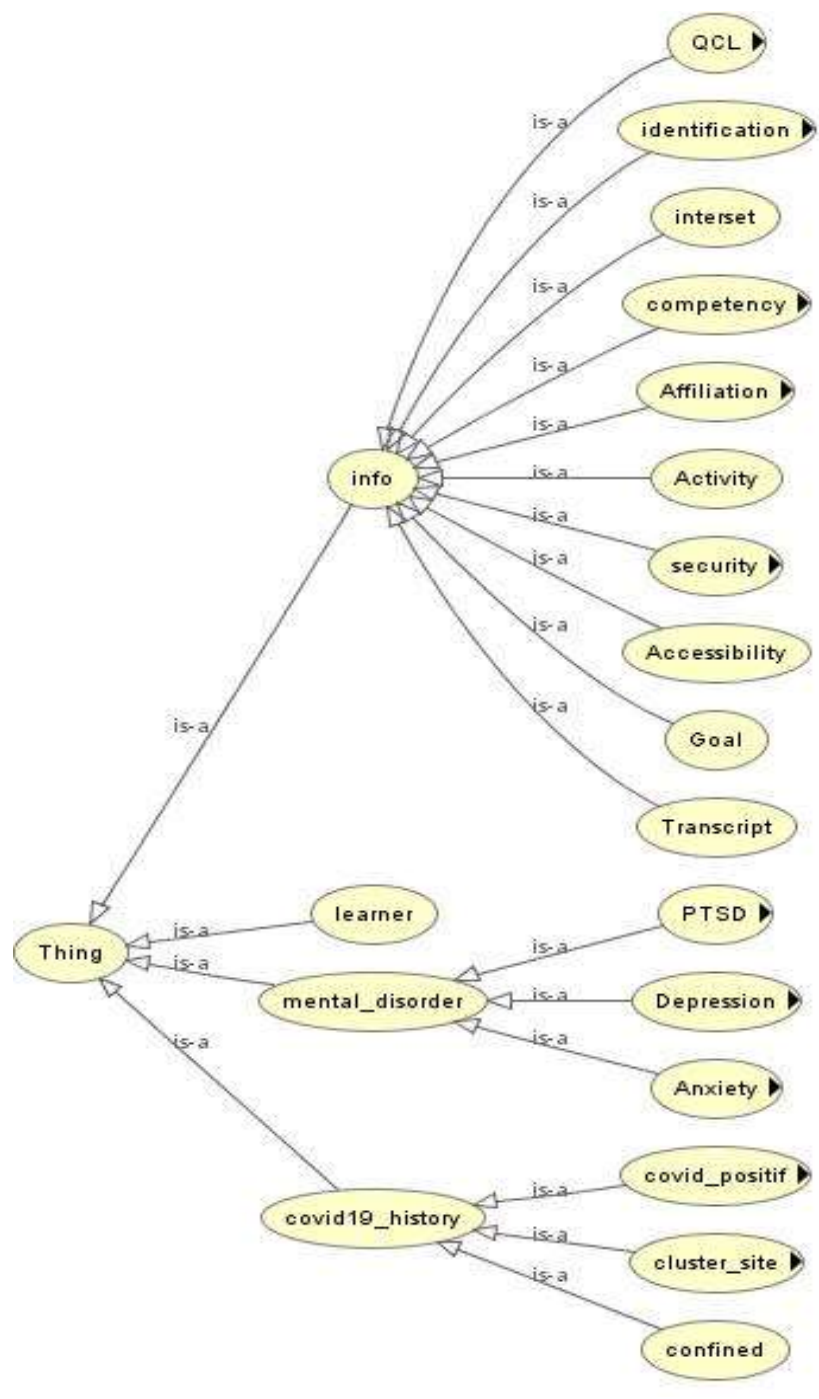

Fig. 6. Learner Model Ontology.

\section{DISCUSSION AND SUGGESTION}

There are several ontological models in the literature [4-7, $9,18]$ presenting different aspects and characteristics of the learner such as abilities, learning style, prior knowledge, preferences, motivation, goals and many others. However, none of these models address criteria such as the mental disorders that the learner may have, especially in times of crisis, also the covid_history feature that is special to the time of pandemic and will be in use for the school and universities to control the pandemic situation.
Table II gives a comparison between the different learner models $[5-8,17,18,43$,$] and the proposed model. It shows the$ difference between the models in the literature and our model according to the learner characteristics. The COVID-19 history data were not discussed due to its direct connection to the pandemic situation and never been discussed before in any work.

The table confirms that the mental health of learner is not taken in consideration despite its relevance to the learner ability to learn.

The proposed approach aims to give a representation that brings together the pedagogical and psychological characteristics, but also the health risks generated by the epidemic on the learners, by answering the three questions specified in the previous section. The first question with the objective of specifying the essential characteristics of the learner. Thus, our ontology defines the main characteristics of the learner (coordinates, diplomas, level, interest, etc.). It can be used in adaptive hypermedia systems, to propose specific courses according to the learner's objective and abilities, also according to his level of knowledge after having passed tests to detect it. The system will adapt a set of courses according to the learner's profile. During the learning session, the system can update learner information.

The second question addresses the damaging effects of the pandemic on the mental health of learners. According to Cao et al. anxiety, depression, and Post Traumatic Stress Disorder (PTSD) are the most diagnosed mental disorders among learners [26]. Our ontology can be used in systems to detect these disorders through psychological self-assessments that the learner can go through in order to provide psychological support or counselling, and eventually enable them to overcome these difficult circumstances. Or in educational systems to suggest less overwhelming educational objects. To give him more time for his homework, or other, taking into consideration his psychological state.

TABLE II. COMPARATIVE STUdy BETWEEN THE PROPOSED MOdEL AND SURVEYED MODEL

\begin{tabular}{|c|c|c|c|c|c|c|c|c|}
\hline \multicolumn{2}{|c|}{ Learner model ontology } & [5] & [6] & [7] & [8] & [17] & [18] & [43] \\
\hline \multirow{5}{*}{$\begin{array}{l}\text { Personal } \\
\text { data }\end{array}$} & Accessibility & & & & + & & + & + \\
\hline & Affiliation & + & & & + & & + & \\
\hline & Identification & + & + & + & + & + & + & + \\
\hline & Interest & + & + & & + & & + & \\
\hline & Security & & + & & + & & + & \\
\hline \multirow{6}{*}{$\begin{array}{l}\text { Pedagogica } \\
1 \text { data }\end{array}$} & Activity & & + & & + & & + & \\
\hline & Competency & + & + & + & + & + & + & + \\
\hline & Goal & + & + & & + & & + & + \\
\hline & QCL & + & + & & + & & + & + \\
\hline & Relationships & + & & & + & & & \\
\hline & Transcript & + & & + & + & + & & + \\
\hline \multirow{3}{*}{$\begin{array}{l}\text { Psychologi } \\
\text { cal Data }\end{array}$} & Anxiety & & & & + & & & \\
\hline & PTSD & & & & & & & \\
\hline & Depression & & & & & & & \\
\hline
\end{tabular}


The final question that the ontology should answer is that of the health of the learner in relation to Covid-19. The proposed ontology ensures the detection if the learner or a family member is affected by the virus. It can be used to warn classmates, teachers and others who may be in contact with him, or in other examples if one of the learners' reports that he is living in a cluster site, this information can be used to identify others who are living in the same neighborhood to transfer them directly to distance learning.

The proposed ontological model is able to answer all three research (competency) questions. It is subsequently able to provide a representation of learners during and after the COVID-19 pandemic and in other times of crisis.

Reusability is also a very important part of our work. Besides the three examples of uses presented. The proposed ontology can be used and reused in different situations and different areas, not only in the case of a pandemic but in other times of social or personal crisis, including, but not limited to, natural disasters, terrorist attacks, loss of a loved one, divorce, etc. The proposed ontology allows the detection of the three mental disorders, but it gives the possibility to add others with their different scales according to the need. It gathers pedagogical, psychic, and health criteria related to COVID-19, but we can always add other characteristics on the learner such as motivation, commitment or other to enrich the ontology.

\section{CONCLUSION}

In this paper, we modelled, created, and presented a learner model ontology during a time of crisis precisely in the Covid19 pandemic. The ontology was constructed according to the knowledge engineering methodology using the Protege 4.3 Ontology Editor, and validated by the integrated HERMIT1.3.8 reasoner to validate its consistency, and to verify that it did not contain contradictory classes.

The focus was on the mental and physical health of the learners during and after Covid-19. The recorded information about the learner can be categorized into three main classes, the first one capturing academic information compliant with the IMS-LIP standard. The second collects information related to the mental disorders that the learner may have (anxiety, depression, PTSD) and their respective degrees of severity. The last one is the most related to Covid-19, it gathers the necessary information on the state of health of the learner if he is contaminated or at risk of contracting the virus.

Our approach gives the possibility to add other mental disorders with their scale for diagnosis if necessary and even other scale to the disorders that were mentioned in several conditions of a crisis in society (pandemic, natural disaster, terrorist attack, ...) or even in the case of personal or family crises (loss of a loved one, divorce ...). The choice to use ontologies to model our learner profile is as a consequence of their reusability, and in a context of adapting educational content, ontologies allow the semantic annotation of data and offer a better organization, indexing and management of data in order to provide the learner with relevant educational supports according to his profile. This ontology is a work in progress that we are working on improving considering different characteristic as the learning styles, the preferences, and the different constraints that the learner might be confronted with as low internet connection or lack of it.

The next step will be to integrate the ontology in an adaptive system, regroup similar learners for a better collaborative work, all to assure a good learning experience for every learner despite the circumstances.

\section{ACKNOWLEDGMENT}

This work is supported and financed by the University Hassan II of Casablanca- Morocco and The National Scientific research and technology Center (CNRST) under the program "support program for scientific and technological research related to covid-19", project "Elaboration of a psychological and pedagogical support platform".

\section{REFERENCES}

[1] U. Nations and Secretary-General, "Policy Brief: Education during COVID-19 and beyond," 2020. [Online]. Available: https://unsdg.un.org/resources/policy-brief-education-during-covid-19and-beyond.

[2] S. Cassidy, "Exploring individual differences as determining factors in student academic achievement in higher education," Studies in Higher Education, vol. 37, no. 7, pp. 793-810, 2012/11/01 2012, doi: 10.1080/03075079.2010.545948.

[3] A. Abyaa, M. K. Idrissi, and S. Bennani, "Learner modelling: systematic review of the literature from the last 5 years," Educational Technology Research and Development, vol. 67, no. 5, pp. 1105-1143, 2019.

[4] A. E. Labib, J. H. Canós, and M. C. Penadés, "On the way to learning style models integration: a Learner's Characteristics Ontology," Computers in Human Behavior, vol. 73, pp. 433-445, 2017.

[5] K. Rezgui, H. Mhiri, and K. Ghédira, "An Ontology-based Profile for Learner Representation in Learning Networks," International Journal of Emerging Technologies in Learning, vol. 9, no. 3, 2014.

[6] S. Ouf, M. Abd Ellatif, S. E. Salama, and Y. Helmy, "A proposed paradigm for smart learning environment based on semantic web," Computers in Human Behavior, vol. 72, pp. 796-818, 2017.

[7] S. A. Hosseini, A.-R. H. Tawil, H. Jahankhani, and M. Yarandi, "Towards an Ontological Learners' Modelling Approach for Personalised E-Learning," International Journal of Emerging Technologies in Learning, vol. 8, no. 2, 2013.

[8] D. Milosevic, M. Brkovic, and D. Bjekic, "Designing lesson content in adaptive learning environments," International Journal of Emerging Technologies in Learning (iJET), vol. 1, no. 2, 2006.

[9] R. Hammad and M. Odeh, "eLEM: A novel e-learner experience model," International Arab Journal of Information Technology, vol. 14, no. 4A, 2017.

[10] P. Brusilovsky and E. Millán, "User models for adaptive hypermedia and adaptive educational systems," in The adaptive web: Springer, 2007, pp. 3-53.

[11] D. Vrandečić, "Ontology evaluation," in Handbook on ontologies: Springer, 2009, pp. 293-313.

[12] V. Vagale and L. Niedrite, "Learner Model's Utilization in the ELearning Environments," in DB\&Local Proceedings, 2012: Citeseer, pp. 162-174.

[13] S. Somyürek, "Student modeling: Recognizing the individual needs of users in e-learning environments," Journal of Human Sciences, vol. 6, no. 2, pp. 429-450, 2009.

[14] N. F. Noy and D. L. McGuinness, "Ontology development 101: A guide to creating your first ontology," ed: Stanford knowledge systems laboratory technical report KSL-01-05 and ..., 2001.

[15] M. Al-Yahya, R. George, and A. Alfaries, "Ontologies in E-learning: review of the literature," International Journal of Software Engineering and Its Applications, vol. 9, no. 2, pp. 67-84, 2015.

[16] M. Winter, C. A. Brooks, and J. E. Greer, "Towards Best Practices for Semantic Web Student Modelling," in AIED, 2005, pp. 694-701. 
[17] A. Behaz and M. Djoudi, "Approche de Modélisation d'un Apprenant à base d'Ontologie pour un Hypermédia adaptatif Pédagogique," in CIIA, 2009.

[18] O. Zine, A. Derouich, and A. Talbi, "IMS Compliant Ontological Learner Model for Adaptive E-Learning Environments," International Journal of Emerging Technologies in Learning (iJET), vol. 14, no. 16, pp. 97-119, 2019.

[19] A. Paramythis and S. Loidl-Reisinger, "Adaptive learning environments and e-learning standards," in Second european conference on e-learning, 2003, vol. 1, no. 2003, pp. 369-379.

[20] IEEE P1484.2.1/D8, PAPI Learner - Core Features, I. C. Society, 2001. [Online]. Available: https://studylib.net/doc/18787880/ieeep1484.2.1-d8--papi-learner-\%E2\%80\%94-core-features.

[21] IMS Learner Information Packaging Information Model Specification v1.0, I. G. L. Consortium, 2001. [Online]. Available: http://www.imsglobal.org/profiles/lipinfo01.html.

[22] O. HULL, "Metadata standards for the description of portal users: a review," 2003.

[23] C. Jacquiot, "Modélisation logique et générique des systèmes d'hypermédias adaptatifs," PhD thesis, Department of Computer science, France, Supelec, 2006.

[24] D. Talevi et al., "Mental health outcomes of the CoViD-19 pandemic," Rivista di psichiatria, vol. 55, no. 3, pp. 137-144, 2020.

[25] C. González-Sanguino et al., "Mental health consequences during the initial stage of the 2020 Coronavirus pandemic (COVID-19) in Spain," Brain, Behavior, and Immunity, vol. 87, pp. 172-176, 2020/07/01/ 2020, doi: https://doi.org/10.1016/j.bbi.2020.05.040.

[26] W. Cao et al., "The psychological impact of the COVID-19 epidemic on college students in China," Psychiatry research, p. 112934, 2020.

[27] M. Blais and L. Baer, "Understanding rating scales and assessment instruments," in Handbook of clinical rating scales and assessment in psychiatry and mental health: Springer, 2009, pp. 1-6.

[28] C. Cusin, H. Yang, A. Yeung, and M. Fava, "Rating scales for depression," in Handbook of clinical rating scales and assessment in psychiatry and mental health: Springer, 2009, pp. 7-35.

[29] J. B. Williams, "Standardizing the Hamilton Depression Rating Scale: past, present, and future," European Archives of Psychiatry and Clinical Neuroscience, vol. 251, no. 2, pp. 6-12, 2001.

[30] M. Zimmerman, J. H. Martinez, D. Young, I. Chelminski, and K. Dalrymple, "Severity classification on the Hamilton depression rating scale," Journal of affective disorders, vol. 150, no. 2, pp. 384-388, 2013.

[31] A. T. Beck, R. A. Steer, and G. Brown, "Beck depression inventory-II," Psychological Assessment, 1996.

[32] A. J. Rush et al., "The 16-Item Quick Inventory of Depressive Symptomatology (QIDS), clinician rating (QIDS-C), and self-report
(QIDS-SR): a psychometric evaluation in patients with chronic major depression," Biological psychiatry, vol. 54, no. 5, pp. 573-583, 2003.

[33] L. Marques, A. Chosak, N. M. Simon, D.-M. Phan, S. Wilhelm, and M. Pollack, "Rating scales for anxiety disorders," in Handbook of clinical rating scales and as-sessment in psychiatry and mental health: Springer, 2009, pp. 37-72.

[34] E. Thompson, "Hamilton rating scale for anxiety (HAM-A)," Occupational Medi-cine, vol. 65, no. 7, p. 601, 2015.

[35] R. L. Spitzer, K. Kroenke, J. B. Williams, and B. Löwe, "A brief measure for as-sessing generalized anxiety disorder: the GAD-7," Archives of internal medicine, vol. 166, no. 10, pp. 1092-1097, 2006.

[36] K. Kroenke, R. L. Spitzer, J. B. Williams, P. O. Monahan, and B. Löwe, "Anxiety disorders in primary care: prevalence, impairment, comorbidity, and detection," Annals of internal medicine, vol. 146, no. 5, pp. 317-325, 2007.

[37] E. Moreno et al., "Factorial invariance of a computerized version of the GAD-7 across various demographic groups and over time in primary care patients," Journal of affective disorders, vol. 252, pp. 114-121, 2019.

[38] A. P. Association, Diagnostic criteria from dsM-iV-tr. American Psychiatric Pub, 2000.

[39] D. D. Blake et al., "The development of a clinician-administered PTSD scale," Journal of traumatic stress, vol. 8, no. 1, pp. 75-90, 1995.

[40] F. W. Weathers, B. T. Litz, D. S. Herman, J. A. Huska, and T. M. Keane, "The PTSD Checklist (PCL): Reliability, validity, and diagnostic utility," in annual convention of the international society for traumatic stress studies, San Antonio, TX, 1993, vol. 462: San Antonio, TX.

[41] A. J. Lang and M. B. Stein, "An abbreviated PTSD checklist for use as a screening instrument in primary care," Behaviour research and therapy, vol. 43, no. 5, pp. 585-594, 2005.

[42] M. Grüninger and M. S. Fox, "Methodology for the design and evaluation of ontologies," 1995.

[43] D. Nurjanah, "LifeOn, a ubiquitous lifelong learner model ontology supporting adaptive learning," in 2018 IEEE Global Engineering Education Conference (EDUCON), 2018: IEEE, pp. 866-871.

[44] M. R. F. Sani, N. Mohammadian, and M. Hoseini, "Ontological learner modeling," Procedia-Social and Behavioral Sciences, vol. 46, pp. 52385243, 2012.

[45] L. Oubahssi and M. Grandbastien, "From learner information packages to student models: Which continuum?," in International Conference on Intelligent Tutoring Systems, 2006: Springer, pp. 288-297.

[46] M. G. Craske, S. L. Rauch, R. Ursano, J. Prenoveau, D. S. Pine, and R. E. Zin-barg, "What is an anxiety disorder?," Focus, vol. 9, no. 3, pp. 369-388, 2011. 